\title{
Sharp Wave Ripples during Visual Exploration in the Primate Hippocampus
}

\author{
Timothy K. Leonard, ${ }^{1}$ Jonathan M. Mikkila, ${ }^{1}$ Emad N. Eskandar, ${ }^{2}$ - Jason L. Gerrard, ${ }^{2}$ Daniel Kaping, ${ }^{3}$ Shaun R. Patel, ${ }^{2}$ \\ Thilo Womelsdorf, ${ }^{3}$ and $\odot$ Kari L. Hoffman ${ }^{1,3}$ \\ Departments of ${ }^{1}$ Psychology and ${ }^{3}$ Biology, Centre for Vision Research, York University, Toronto, Ontario M3J 1P3, Canada, and ${ }^{2}$ Nayef \\ Al-Rodhan Laboratories, Department of Neurosurgery, Massachusetts General Hospital, Boston, Massachusetts 02114
}

\begin{abstract}
Hippocampal sharp-wave ripples (SWRs) are highly synchronous oscillatory field potentials that are thought to facilitate memory consolidation. SWRs typically occur during quiescent states, when neural activity reflecting recent experience is replayed. In rodents, SWRs also occur during brief locomotor pauses in maze exploration, where they appear to support learning during experience. In this study, we detected SWRs that occurred during quiescent states, but also during goal-directed visual exploration in nonhuman primates (Macaca mulatta). The exploratory SWRs showed peak frequency bands similar to those of quiescent SWRs, and both types were inhibited at the onset of their respective behavioral epochs. In apparent contrast to rodent SWRs, these exploratory SWRs occurred during active periods of exploration, e.g., while animals searched for a target object in a scene. SWRs were associated with smaller saccades and longer fixations. Also, when they coincided with target-object fixations during search, detection was more likely than when these events were decoupled. Although we observed high gamma-band field potentials of similar frequency to SWRs, only the SWRs accompanied greater spiking synchrony in neural populations. These results reveal that SWRs are not limited to off-line states as conventionally defined; rather, they occur during active and informative performance windows. The exploratory SWR in primates is an infrequent occurrence associated with active, attentive performance, which may indicate a new, extended role of SWRs during exploration in primates.
\end{abstract}

Key words: change detection; macaque; natural scenes; search; sleep; theta

\section{Significance Statement}

Sharp-wave ripples (SWRs) are high-frequency oscillations that generate highly synchronized activity in neural populations. Their prevalence in sleep and quiet wakefulness, and the memory deficits that result from their interruption, suggest that SWRs contribute to memory consolidation during rest. Here, we report that SWRs from the monkey hippocampus occur not only during behavioral inactivity but also during successful visual exploration. SWRs were associated with attentive, focal search and appeared to enhance perception of locations viewed around the time of their occurrence. SWRs occurring in rest are noteworthy for their relation to heightened neural population activity, temporally precise and widespread synchronization, and memory consolidation; therefore, the SWRs reported here may have a similar effect on neural populations, even as experiences unfold.

\section{Introduction}

The sharp-wave ripple (SWR) is a highly synchronized hippocampal field potential complex associated with widespread ac- tivation of the neocortex (Chrobak, and Buzsáki, 1994; Siapas and Wilson, 1998; Sirota et al., 2003; Battaglia et al., 2004; Isomura et al., 2006; Mölle et al., 2006; Logothetis et al., 2012). During SWRs, internally generated sequences of cell-specific firing ("replay") occur locally (Wilson and McNaughton, 1994;

Correspondence should be addressed to Kari L. Hoffman, Department of Psychology, Department of Biology, Centre for Vision Research, Toronto, 0N M3J 1P3. E-mail: khoffman@yorku.ca.

D. Kaping's present address: Department of Neuroscience, Karolinska Institute, 17165 Solna, Sweden.

J.L. Gerrard's present address: Yale Neurosurgery, New Haven, CT 06520-8082.

DOI:10.1523/JNEUROSCI.0864-15.2015

Copyright $\odot 2015$ Leonard et al.

This is an Open Access article distributed under the terms of the Creative Commons Attribution License Creative Commons Attribution 4.0 International, which permits unrestricted use, distribution and reproduction in any medium provided that the original work is properly attributed. 
Kudrimoti et al., 1999; Csicsvari et al., 2000; Gerrard et al., 2001; Louie and Wilson, 2001; Foster and Wilson, 2006) and at remote neocortical sites (Qin et al., 1997; Ji and Wilson, 2007; Peyrache et al., 2009; Benchenane et al., 2010). Both SWRs and these replay events are most frequently observed during slow-wave sleep (SWS) and periods of waking immobility; furthermore, interruption of SWRs during these states leads to memory deficits (Girardeau et al., 2009; Ego-Stengel and Wilson, 2010). As a result, SWRs are widely believed to underlie memory consolidation during quiescence (Buzsáki, 1989, 1996; Hoffman et al., 2007; Battaglia et al., 2011).

SWRs, however, are also seen during active waking states. These SWRs are termed “exploratory” SWRs (eSWRs; O’Neill et al., 2006). In rats, their occurrence during goal-directed tasks predicts correct performance/memory (Dupret et al., 2010; Pfeiffer and Foster, 2013; Singer et al., 2013) and their interruption during these active states impairs task performance (Jadhav et al., 2012). Detection criteria for eSWRs require low to no movement velocity, to prevent false-positive detection of theta-related highfrequency activity seen during running (but see Kemere et al., 2013). Although eSWRs, by definition, occur during slow or no movement during the task, their occurrence during the task opens up the possibility that SWRs have other roles, including those associated with learning or recollection within epochs of exploration, decision making, and goal acquisition (O'Neill et al., 2010; Carr et al., 2011; Girardeau and Zugaro, 2011; Pezzulo et al., 2014; Yu and Frank, 2015).

In humans and macaques, SWRs have only been described during inactive states; during extended periods of quiescence, including SWS [quiescent state SWRs (qSWRs)]; or during inattentive, quiet wakefulness in an experimental booth or bedsidebut in any case with relative inactivity and immobility during waking [waking "inactive" SWRs (iSWRs); Bragin et al., 1999; Skaggs et al., 2007; Axmacher et al., 2008; Le Van Quyen et al., 2008, 2010; Logothetis et al., 2012]. It is as yet unclear whether or not SWRs also play a role in goal-directed visual exploration in primates, e.g., visual scanning behaviors observed as sequences of gaze fixations in which different parts of a scene are successively foveated. Such visual search comprises a major- even defaultclass of exploration that supports learning of one's surroundings and that generalizes across many primate species, including humans. If SWRs in primates occur as they do in rats, we expect that SWRs should occur during goal-directed visual exploration tasks.

Here, we set out to determine the behavioral states and behavioral correlates when primate SWRs occur and to compare characteristics of SWR events to those of high-gamma $(\sim 80-120 \mathrm{~Hz})$ and high-frequency oscillations (HFOs; $110-160 \mathrm{~Hz}$ ) that occur during exploration and other active waking behaviors (Csicsvari et al., 1999; Tort et al., 2008, 2013; Jackson et al., 2011; Sullivan et al., 2011; Scheffer-Teixeira et al., 2012; Buzsáki and Schomburg, 2015). Studies of SWRs in humans and monkeys have not evaluated the relationship between these high-frequency events and SWRs with overlapping frequency bands, though conventional methods could falsely detect these events as SWRs. We found that SWRs differed from other high-frequency events, and that they appeared not only in quiescence, but also during goal-directed visual exploration, and at higher rates when coinciding with target fixations on successful trials.

\section{Materials and Methods}

Subjects and experimental design. Four adult macaques (Macaca mulatta; m1, m2: female; m3, m4: male) completed visual target-detection tasks during daily recording sessions. Each animal completed one of three specific task variations, but all required the animals to find and select a correct target object from nontargets within a visual array for fluid reward. Cues that determined the correct visual target were photorealistic visual scenes for $\mathrm{m} 1, \mathrm{~m} 2$, and $\mathrm{m} 3$, and simple color cues for $\mathrm{m} 4$. Both $\mathrm{m} 1$ and $\mathrm{m} 2$ performed a flicker change-detection task, requiring that gaze remains in the target region for a prolonged (>800 ms) "selection" duration, thereby indicating detection of a scene-unique target object. The target object was cued by appearing and disappearing within the scene, in an alternating pattern, every $500 \mathrm{~ms}$, with an intervening $50 \mathrm{~ms}$ grayscreen gap that obscured the object change perceptually. Such tasks require effortful search to detect the changing part of the scene in humans and macaques (Chau et al., 2011). See previous reports (Chau et al., 2011; Hoffman et al., 2013) for more detailed descriptions of the changedetection task and its relation to hippocampal function. $\mathrm{m} 3$ also learned scene-object associations, but the correct (i.e., fluid rewarded) response required manual selection of the correct response object from an array that followed scene presentation. Most of the scene-object location pairings were new each day, and learned by trial and error during the session, whereas a well learned subset of pairings were repeated daily. $\mathrm{m} 4$ performed a task requiring visually cued target selection (selective attention) that led to an additional conditional visuomotor response (Shen et al., 2015). The initial visual cue was a color indicating the correct target object to attend on that trial; changes in this target indicated the correct response location (the conditional visuomotor response), whereas changes in nontargets indicated alternate response locations. The conditional response- a saccade to the correct response location immediately following the target object change-disambiguated which target had been attended.

For all animals, an intertrial interval (ITI) followed each trial. ITIs lasted 2-20 s; both room and screen were darkened throughout the epoch. We took these periods as quiet waking "inactive" behavioral epochs (iSWRs), as they follow immediately reward on correct trials, and marked a transition between the end of one trial and the beginning of the next, akin to startbox or reward locations in rat experiments. Finally, for $\mathrm{m} 1, \mathrm{~m} 2$, and $\mathrm{m} 3$, the daily sessions began and ended with a period of $\geq 10$ min when no stimulus was presented within the darkened booth and animals were allowed to sleep or sit quietly (quiescent period, for qSWRs).

Eye movements were recorded using video-based eye tracking $(\mathrm{m} 1, \mathrm{~m} 2$ : iViewX Hi-Speed Primate remote infrared eye tracker, SensoMotoric Instruments; m3, m4: iScan, Iscan). Infrared tracking allows monitoring of eye movements only when the eye is open, calibrated to the display screen. Therefore, in the present study, the signal is shown only in case of such eye movements. All experimental protocols were conducted with approval from the local ethics and animal care authorities.

Electrophysiological recordings. Animals $\mathrm{m} 1-\mathrm{m} 3$ were implanted chronically with platinum/tungsten multicore tetrodes (96 $\mu \mathrm{m}$ outer diameter; Thomas Recordings) lowered into the CA3/DG region of hippocampus. $\mathrm{m} 4$ was recorded with 125 and $200 \mu \mathrm{m}$ tungsten microelectrodes (FHC) lowered daily, with trajectories aimed at CA3/DG and CA1/subiculum. Locations are estimated from chamber insert locations in magnetic resonance (MR) images ( $\mathrm{m} 4$ ), from postexplant MR images (m1), and from MR/CT (computed tomography) coregistration of electrode position (m3); and from functional characterization based on expected white/gray matter and ventricle transitions in depth during lowering, followed by the appearance of SWRs (m1, m2, m3; Fig. $1 A, B, E)$. We observed SWRs only in limited ranges of depth across the chronically implanted tetrodes, within which we encountered single units. These units were predominantly complex spiking (CS), or "bursting" cells, with proportions matching hippocampal distributions (88\%) rather than the lower proportions characteristic of surrounding areas (Skaggs et al., 2007). Unlike rodent dorsal CA1, we did not observe sharp-wave polarity reversals across the cell layer.

For $\mathrm{m} 4$, local field potentials (LFPs) were digitally sampled at $1 \mathrm{kHz}$ using a multichannel processor (Map System, Plexon; m2) and for $\mathrm{m} 1-\mathrm{m} 3$ potentials were sampled at $32 \mathrm{kHz}$ using a Digital Lynx acquisition system (Neuralynx) and filtered between $0.5 \mathrm{~Hz}$ and $2 \mathrm{kHz}$. The recording chamber was used as reference for all but $\mathrm{ml}$, who had a local reference at the end of the array "bundle," $\sim 5 \mathrm{~mm}$ above the recording 
A

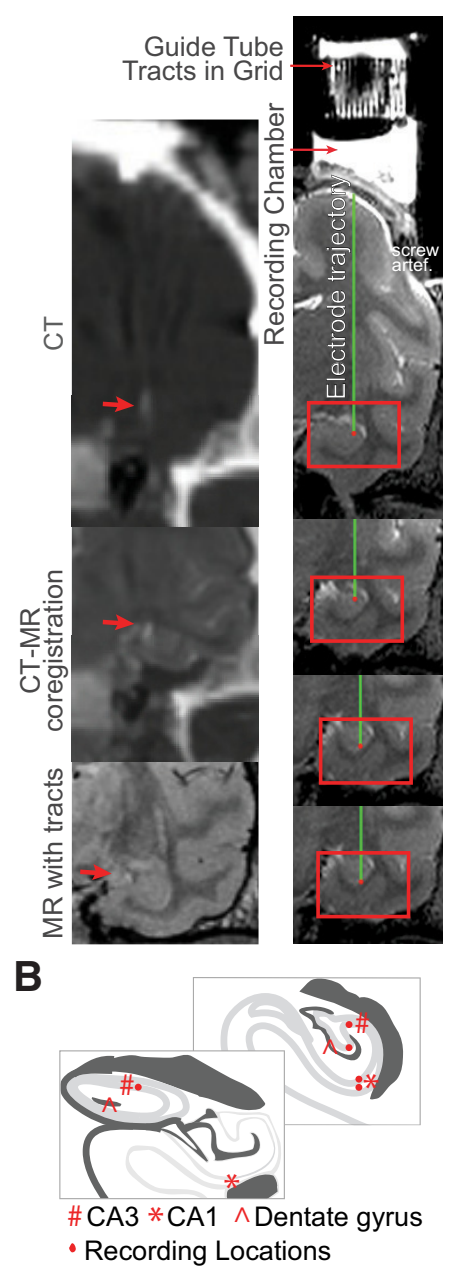

C

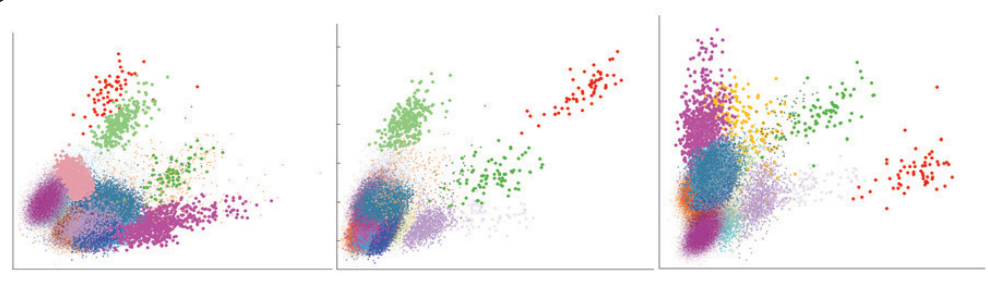

D

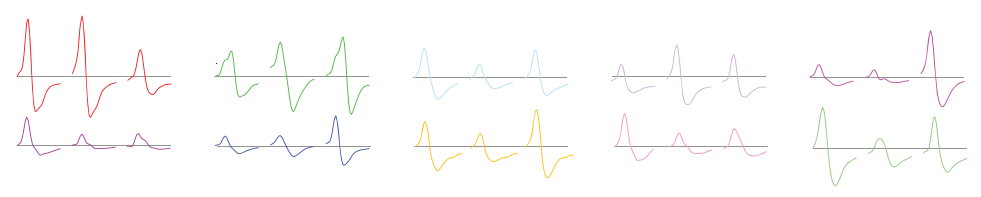

E

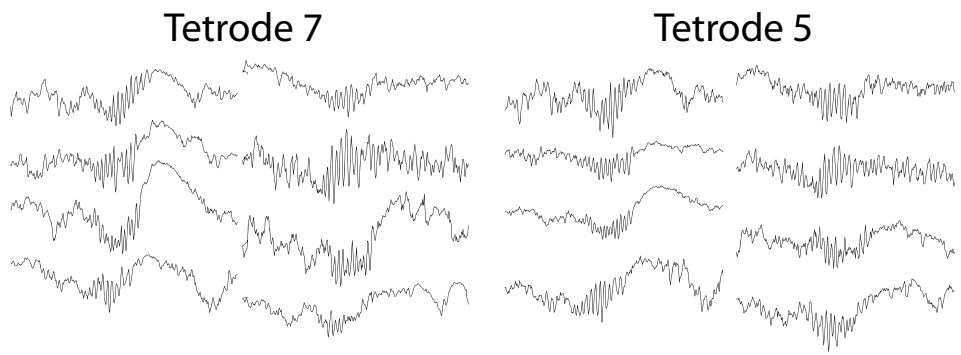

$\mathbf{F}$

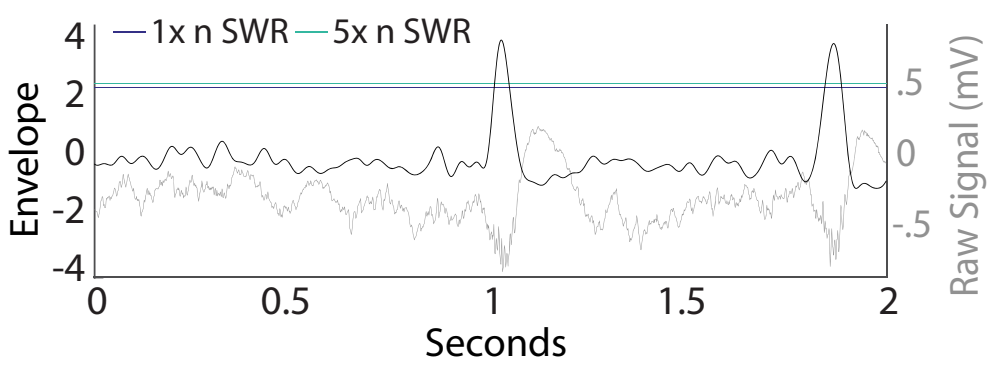

Figure 1. A, Coronal MR and CT images of hippocampal electrode trajectories. CT image of tract (top) coregistered and superimposed on MR image (middle) shows the electrode tip (white puff) registered to CA3/DG of hippocampus for $\mathrm{m} 3$ (indicated in $\boldsymbol{B}$ ), closely matching the MR with tracts seen for $\mathrm{m} 1$ (bottom). Top, Right, Location of the recording chamber on the skull for $\mathrm{m} 4$, with electrode grid locations (white vertical tracts). The reconstructed electrode trajectory (green) and tip locations (red) reveal the hippocampal recording sites, primarily in CA3/DG. $\boldsymbol{B}$, Schematic drawings of coronal sections of the hippocampal formation. Red dots, Recording locations; \#, CA3; *, CA1; , dentate gyrus. Illustrations adapted from Saleem and Logothetis (2012). C, Spike scatter plots from recordings on one tetrode based on energy (same tetrode and session as in $\boldsymbol{D}$ and $\boldsymbol{E}$ ). $\boldsymbol{D}$, Examples of the average waveforms of units isolated from one tetrode, during the same session in which SWRs were recorded (shown in $\boldsymbol{E}$ ). Waveforms are shown inverted, by convention. $\boldsymbol{E}$, Broadband traces of SWR events from $\mathrm{m} 1$. Tetrode 7 was used for SWR detection in this session; the simultaneously recorded activity on Tetrode 5 is shown on the corresponding row. SWRs were observed in a limited range of depth across the chronically implanted tetrodes, where units were also observed $(\boldsymbol{C}, \boldsymbol{D}) . \boldsymbol{F}$, lllustration of the ripple envelope threshold method calculated for a single session and applied to an example segment of signal containing two SWRs. Shown in black is an example segment of the recorded signal that contains two ripples. The filtered signal envelope (final detection step) is shown in gray. An envelope $z$-score of 3 (original signal) is shown by a blue horizontal line, and the change in this threshold after simulating a 500\% increase in SWR events is shown in green (see Materials and Methods), revealing the tolerance of the threshold method to large changes in ripple rates.

sites. Single-unit activity was sampled at $32 \mathrm{kHz}$ and filtered between 600 $\mathrm{Hz}$ and $6 \mathrm{kHz}$, recording the waveform for $1 \mathrm{~ms}$ around a thresholdtriggered "spike" event. Single units were isolated using MClust software based on waveshape principle components, energy, peak/valley, and width, across channels (Fig. 1C,D). Care was taken to include only cells that were well isolated, based on $<1 \%$ interspike intervals (ISIs) within 2 $\mathrm{ms}$ and cross-correlograms between bursting cell pairs had to be free of burst-latency peaks (asymmetric, $<10 \mathrm{~ms}$ peak that could indicate the erroneous splitting of one CS unit into two; Harris et al., 2000). The CS group included bursting cells (ISI mode peak, $<10 \mathrm{~ms}$, comprising $\geq 10 \%$ of ISIs, and with $<1 \mathrm{~Hz}$ overall firing rate window). Putative interneurons (INs) were cells with $>1 \mathrm{~Hz}$ overall firing rate and no apparent burst mode $(<10 \mathrm{~ms})$ in the ISI histogram.

Hippocampal field potentials change with vigilance state and behaviors, though the patterns observed in human and monkeys (Bódizs et al., 2001; Uchida et al., 2001; Cantero et al., 2003; Moroni et al., 2007; Ta- mura et al., 2013) differ from those that are well characterized in rats (Vanderwolf, 1969; Winson, 1972; Whishaw and Vanderwolf, 1973; Buzsáki et al., 1983; Buzsáki, 1986; Blumberg, 1989). To replicate previous studies' characterization of hippocampal fields during different behavioral states (Clemens et al., 2013; Tamura et al., 2013) and to extend the observations to the present study's behavioral paradigm, we displayed examples of the spectral content of wideband LFP in $3 \mathrm{~s}$ segments taken during search and rest, for the two animals ( $\mathrm{m} 1$ and $\mathrm{m} 2$ ) who had both extended search and quiescent epochs during recordings. Spectra were calculated from the short-time Fourier transform of $600 \mathrm{~ms}$ segments, shifted in $6 \mathrm{~ms}$ increments, windowed with a Hamming window, $1 / f$ normalized ("whitened"), and $z$-transformed. Traces, superimposed onto each spectrogram, corresponding to the raw signal underlying each spectrogram, were taken from the $z$-score transform of the entire session from which each epoch was taken (Fig. 2). In addition, overall spectral power differences between epochs were calculated from the FFT trans- 
A

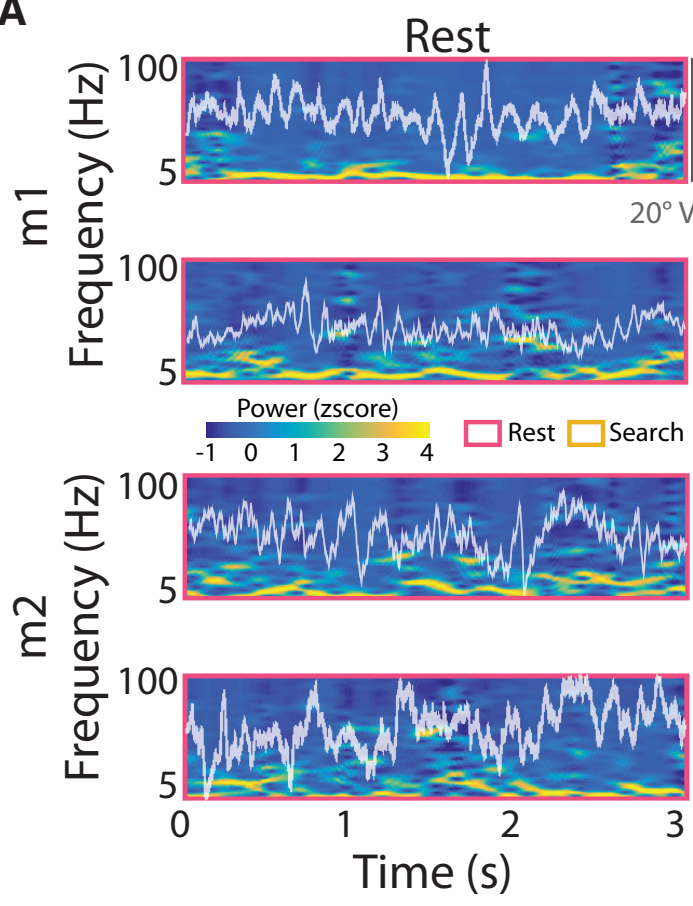

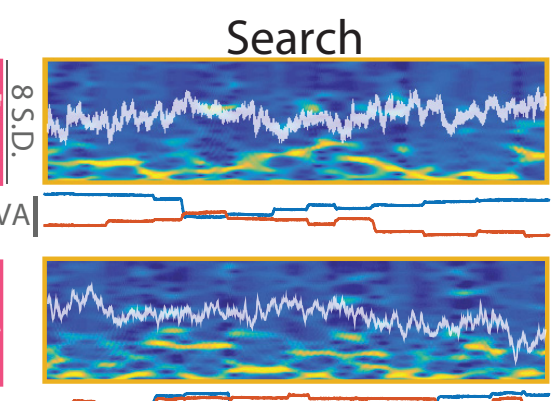

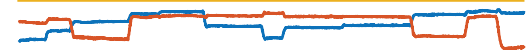

B
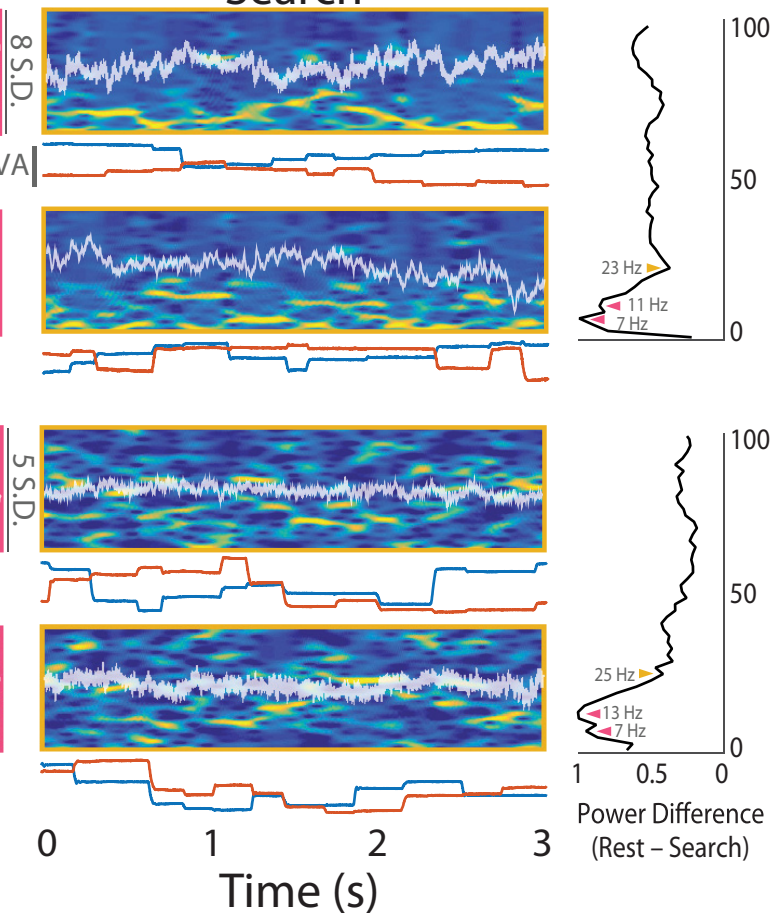

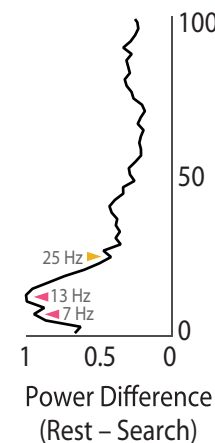

(Rest - Search)

Figure 2. A, Hippocampal activity during different behavioral states, shown for example $3 \mathrm{~s}$ windows during rest epochs (pink outline; left column) and search epochs (orange outline; right column). Recordings from $\mathrm{m} 1$ shown in top two rows and from $\mathrm{m} 2$ on bottom two rows. Time-frequency-resolved spectra were generated from 600 ms segments, shifted in 6 ms increments, windowed with a Hamming window, 1/f normalized, and $z$-transformed. White trace, superimposed on the spectra, is the broadband LFP of the same $3 \mathrm{~s}$ window taken from a $z$-score transform of the entire session. The scale shown in SDs applies to all plots for a given animal. Below search epochs, the concurrent on-screen eye position (horizontal and vertical) are represented as degrees of visual angle (VA; the monitor encompasses $38.5 \times 30.9^{\circ} \mathrm{VA}$ ). $\boldsymbol{B}$, Difference in grand average FFT power across behavioral epochs. For each animal, the average FFTs of epochs for search versus rest were calculated (m1: 66 rest epochs, 1258 search epochs; $\mathrm{m} 2$ : 100 rest epochs, 2584 search epochs). The average FFT for each epoch type was calculated, min-max normalized to a range of 0 -1, and resultant rest values subtracted from the search values. First two peaks (rest $>$ search) are highlighted with pink markers; the trough where search-epoch frequencies become prominent are highlighted with an orange marker.

forms of the full duration of search and quiescent behavioral epochs, where the mean quiescent FFT epoch value was subtracted from the mean FFT search epoch value and minimum-maximum (min-max) normalized (with a scale from 0 to 1 ), to compare with previously reported differences in spectral content by behavioral/vigilance state (Fig. $2 B)$. Differences in spectral content are apparent across behavioral epochs in both animals' recordings. Specifically, power in low frequencies, including $6-10 \mathrm{~Hz}$ "theta," is stronger during quiescent states than during active goal-directed behaviors, consistent with microelectrode recordings in macaques and macroelectrode recordings in humans, localized to the hippocampal formation (Clemens et al., 2013; Tamura et al., 2013).

SWR, $\varepsilon_{80-120}$, and $\varepsilon_{110-160}$ event detection. SWR events were detected by selecting the tetrode/electrode channel with the most visibly apparent ripple activity, filtering that LFP signal $(100-250 \mathrm{~Hz})$, transforming to $z$-scores, rectifying, and bandpass filtering the rectified signal from 1 to $20 \mathrm{~Hz}$, approximating the envelope of the high-frequency signal (Skaggs et al., 2007). Ripple events were defined as threshold crossings 3 SDs above the mean, with a minimum duration of $50 \mathrm{~ms}$, beginning and ending at $1 \mathrm{SD}$.

The use of a variance-based threshold enables comparison to previous studies using this method, though such a threshold is expected to change at least nominally in response to an increase in SWR rate, assuming SWRs increase signal variance. In practice, the sparsity of SWRs relative to the ongoing continuously recorded signal render the impact of different ripple rates on the threshold negligible.

To quantify threshold changes as a function of changes in ripple rate, we selected a session of typical duration $(64.27 \mathrm{~min})$ with a typical number of SWR events $(n=41$ SWR events; total ripple duration of $3.31 \mathrm{~s} ; 0.09 \%$ of session occupied by SWR events). All ripples were removed and the $z$-score of 3 was calculated iteratively, as SWR events were added back into the signal, up to maximum of five times the original number of ripples in this session (205 SWR events). In the present experiments, it would be unlikely to observe a doubling of ripples (200\%), but even after a 500\% increase in ripple events, the underlying signal value for a $z$-score of 3 increased the $z$-score threshold value by 0.1 , or $3.3 \%$ (Fig. $1 F$ ), constituting a negligible impact on ripple rate overall, and no specific grounds that this would vary across statistical conditions.

Based on these criteria, $\mathrm{m} 1$ had 32 sessions with SWRs during both quiescence and task; $\mathrm{m} 2$ had 45 sessions with SWRs during both quiescence and task; $\mathrm{m} 3$ had 5 sessions with SWRs, only 3 of which had SWRs that occurred during the task; and $\mathrm{m} 4$ had 4 task-only sessions with SWRs.

Low- $\varepsilon$ band $\left[\varepsilon_{80-120}\left(\varepsilon_{\mathrm{L}}\right.\right.$, "high gamma")], and high- $\varepsilon$ band $\left[\varepsilon_{110-160}\right.$ $\left(\varepsilon_{\mathrm{H}}\right.$, "HFO")] events were similarly identified, but with the filter criterion set at $80-120$ and $110-160 \mathrm{~Hz}$, respectively, and in both cases identifying peaks as those $>1$ SD. Duplicate $\varepsilon$ and SWR events were labeled as SWRs. Events with a repetition rate $<125 \mathrm{~ms}$ were considered a single event.

Behavioral epoch and SWR rates. eSWRs, iSWRs, and qSWRs (Fig. $3 A$ ) were contrasted by comparing peak frequencies of SWR events from each behavioral state (Fig. 3B). Peak SWR frequencies were calculated on a 200 ms window, centered on the SWR event, with a Hamming window. Peak value locations from the three groups were compared using a KruskalWallis test (KW test). The KW test was used for omnibus tests, whereas the assumption of homogeneity of variance was not met between groups.

To address whether or not elapsed time in a behavioral epoch (search or ITI) influenced the probability of observing SWRs, ripple rates for the first $20 \mathrm{~s}$ of these behavioral epochs were calculated, in $1 \mathrm{~s}$ bins, from all recording sessions with $\geq 1$ ripple (Fig. $3 C$ ). For search epochs, all peri- 
A

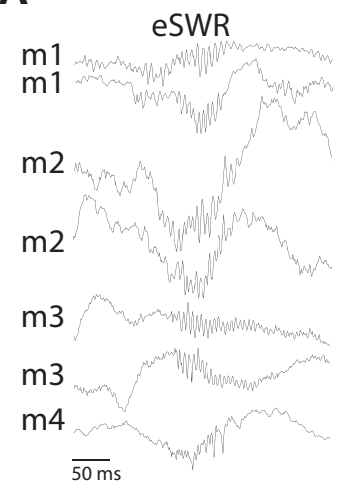

C

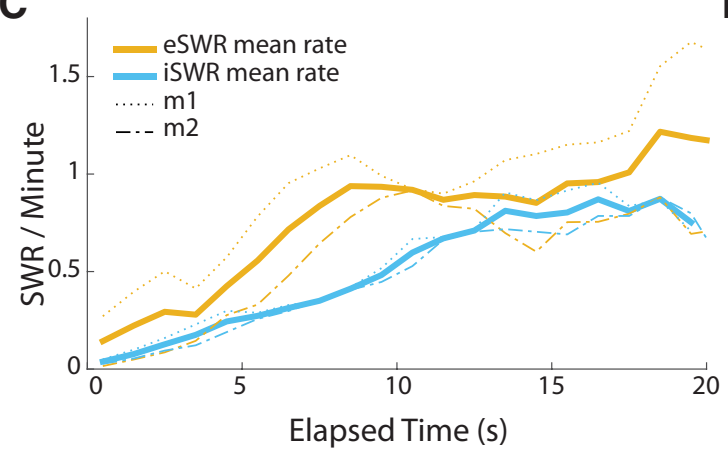

iSWR

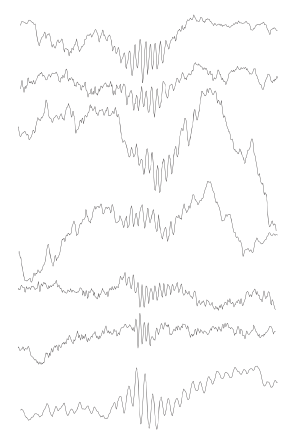

D
B
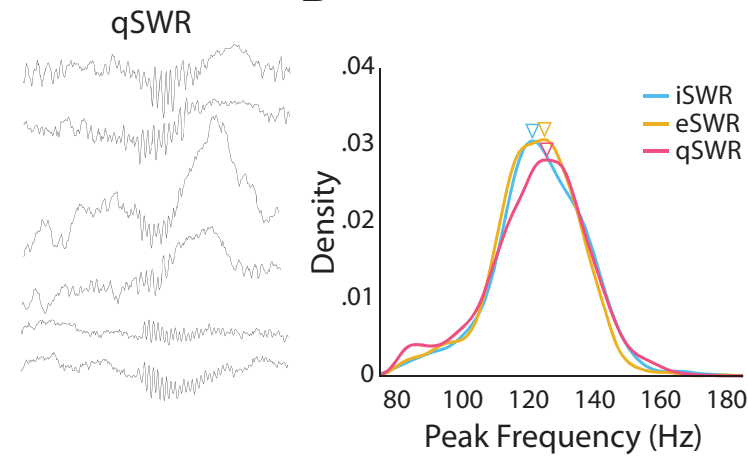

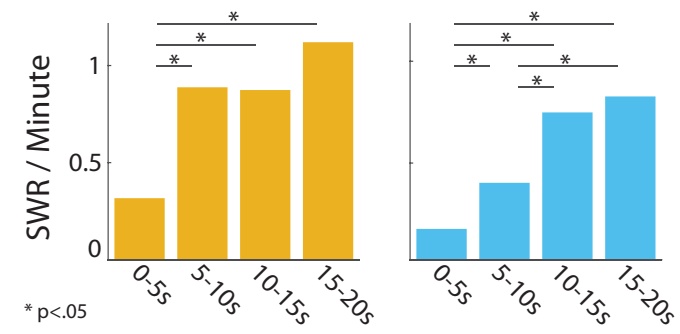

Figure 3. A, Example SWRs during exploratory, inactive, and quiescent periods (eSWR, left; iSWR, middle; qSWR, right, respectively) in four macaques ( $\mathrm{m} 1$ - $\mathrm{m} 4)$. $\boldsymbol{B}$, Kernel density plot comparing peak frequencies among eSWR, iSWR, and qSWR events. Peak frequencies were calculated from $200 \mathrm{~ms}$ windows centered on the SWR event, shown with open triangles. The difference between peak frequencies across behavioral epochs was not significant. C, Overall mean SWR rates during search (eSWR) or inactive (iSWR) periods, relative to epoch onset, are shown in thick lines, and individual mean rates are shown in dashed lines. SWR rates were calculated for the first $20 \mathrm{~s}$ of these epochs, in $1 \mathrm{~s}$ bins, from all recording sessions with $\geq 1$ ripple. For search, only periods with on-screen looking is included. D, The SWR rates, shown in C, for search (left) and inactive (right) behavioral epochs, divided into $5 \mathrm{~s}$ bins. An omnibus test showed rates vary with elapsed time for both search and inactive periods (eSWR: $\chi_{(4)}^{2}=12.3, p=0.006$; iSWR: $\chi_{(4)}^{2}=16.62, p=0.002$ ), results from the follow-up paired comparisons are shown here (Tables 1, 2).

ods where the subject was not looking at the screen were discarded. The $1 \mathrm{~s}$ rate bins were separated into $5 \mathrm{~s}$ groups (at $5,10,15$, and $20 \mathrm{~s}$ ) and tested for significant group differences in ripple rate using a nonparametric omnibus test (KW test). For each behavioral epoch, where the omnibus test was significant, paired comparisons were performed across the groups, using the Wilcoxon rank-sum test, and corrected for false discovery rate with the Benjamini-Hochberg procedure (Benjamini and Hochberg, 1995; Fig. 3D). The rank-sum test was used where paired comparisons on non-normally distributed data were required. For ranksum tests with large samples, the $z$-score is given as effect size. Otherwise the Wilcoxon $U$ test statistic is given. For $\mathrm{m} 4$, the average SWR rate was calculated separately for the first $2 \mathrm{~s}$ of the search epoch, as the average visual search trial duration was $2.99 \mathrm{~s}$ (rate reported in Results; not included in statistics or figures).

Single-unit analysis. We compared firing rates for CSs and putative INs over 28 sessions in which SWR events occurred and cells could be isolated (Fig. 4). We used a previously established measure of population synchronization (Csicsvari et al., 1998), taking the probability of firing of a class of cells $(\mathrm{CS} / \mathrm{IN})$ in a $100 \mathrm{~ms}$ window, centered on the SWR event, and comparing to the probability of firing in a $100 \mathrm{~ms}$ window shifted to $1 \mathrm{~s}$ after the SWR event. The mean rate represents the percentage of cells in a given group active during this window. Due to non-normality of data, a Wilcoxon signed-rank test was used for both cell groups to compare activation during SWRs and control windows. Error bars are the 95\% confidence interval generated from the bootstrapped mean (1000 permutations). This method was also used to compare cell firing rates across event types (SWR $/ \varepsilon_{80-120} / \varepsilon_{110-160}$; see Fig. $6 C$ ).

Parameterization of visual exploration. We evaluated ripple occurrence during the task as a function of visual search. Search comprises (1) sequences of fixations, which are considered the active perceptual component of search, and (2) intervening ballistic movements of the eye (i.e.,

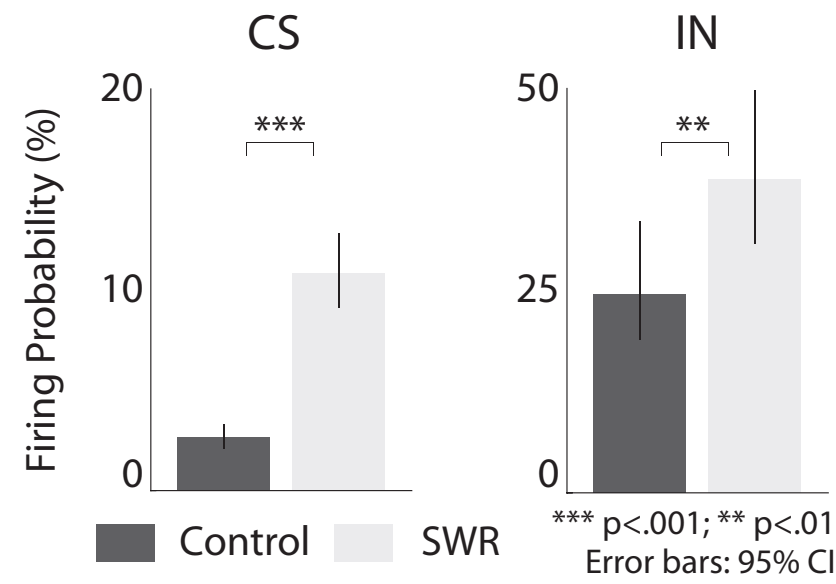

Figure 4. SWR events led to increased population synchrony for complex spike (CS) units and putative interneurons (INs). Probability of firing of a class of cells (CS/IN) was taken from a 100 ms window, centered on the ripple event (SWR, light gray), compared with the probability of firing in a $100 \mathrm{~ms}$ window shifted to $1 \mathrm{~s}$ after the SWR event (control, dark gray). Error bars are bootstrapped $95 \%$ confidence intervals.

"saccades") that enable changes in the visual-field content of fixations (Matin, 1974; Bridgeman et al., 1975; McConkie and Currie, 1996). Because the visual-field resolution is greatest at its center-corresponding to the foveal area of the retina-saccades are used to reposition the eye so that the fovea is directed toward places of interest in the environment. The sequence of these movements, or "scan path," during natural scene viewing can be divided into segments of "looking at" (termed local or 
focal) with shorter saccades than segments of "looking around" (termed ambient or global; Velichkovsky et al., 2005). For target identification in a scene, global segments are also termed "search and comparison" and local segments "detection and verification" (Pomplun et al., 2001). Local segments of search are predictive of successful target detection and of subsequent memory (Henderson et al., 2005; van der Linde et al., 2009) and in humans these fixations are of $\sim 30 \mathrm{~ms}$ longer duration than global fixations. Furthermore, local segments begin well in advance of target detection, and on scene locations other than the target. Therefore, they are considered part of extended, attentive search as opposed to an intrinsic part of detection itself (Scinto et al., 1986). Of importance to our evaluation of behavioral state in the present study, differences between local and global fixation durations still fall within typical duration distributions $(200-300 \mathrm{~ms}$ in humans). In contrast, fixations that include outright cessation in performance ("staring") are unusually long ( $>2$ s; Tole et al., 1982), whereas lapses in attention during performance, (e.g., "mindless" scanning with failure to comprehend text during reading) are associated with shorter durations than expected, especially for fixations that are prolonged during attentive reading due to cognitive load (Schad et al., 2012).

We used these findings to guide search behavior analysis, including possible indicators of inattentive states during search. Specifically, we took the following as measures of search: fixation duration, saccade amplitude, and fixations with gaze directed in the target location ("target fixations"). Previous studies have examined the relationship between spiking or LFPs from the temporal lobe and search/saccadic eye movements in macaques (Ringo et al., 1994; Sobotka et al., 1997, 2002; Purpura et al., 2003; Mruczek and Sheinberg, 2007; Ibbotson et al., 2008; Bartlett et al., 2011; Ibbotson and Krekelberg, 2011; Hoffman et al., 2013; Jutras et al., 2013) and in humans (Hoffman et al., 2013; Andrillon et al., 2015). In contrast, the present study evaluated the as-yet-uncharacterized occurrence of SWRs in relation to visual search.

SWR rates and behavior. To assess whether SWRs were associated with changes in scanning behavior, including pauses in scanning, akin to the slow running or $<2.5 \mathrm{~s}$ pauses in movement used to define eSWRs (O'Neill et al., 2006; Fig. 5A), we first compared fixation durations during SWR events with all remaining fixations during scene search using a ranksum test. We also compared saccade amplitudes flanking SWR-aligned fixations to those occurring at other times during search, again using the rank-sum test. As a follow-up to probe possible interaction between these measures, a logistic regression model was used to identify significant predictors for the occurrence of SWRs, based on fixation durations, saccade amplitudes, and the factor of subject identification. A nonsignificant result on the Hosmer-Lemeshow goodness-of-fit test confirmed the model as a good fit.

To evaluate whether exploratory SWRs coincide with changes in behavioral outcome, SWR rates were computed as a function of lag (number of fixations) from target fixation (Fig. 5B). To account for SWR

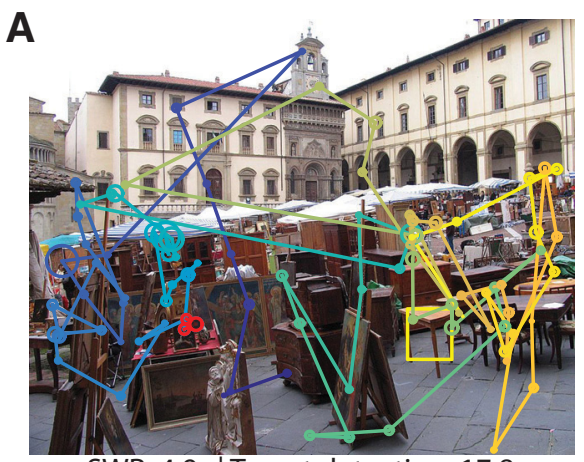

SWR: 4.9s | Target detection: $17.8 \mathrm{~s}$

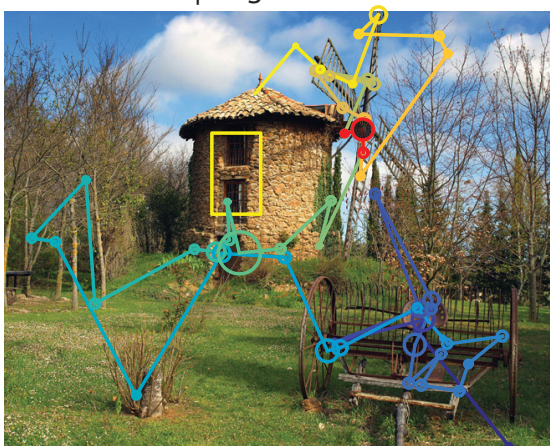

SWR: 10.6s | Target detection: 14.5s

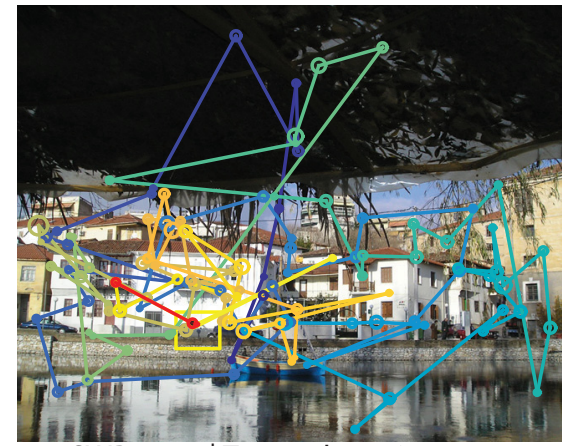

SWR 21.8s | Target detection: $22.2 \mathrm{~s}$

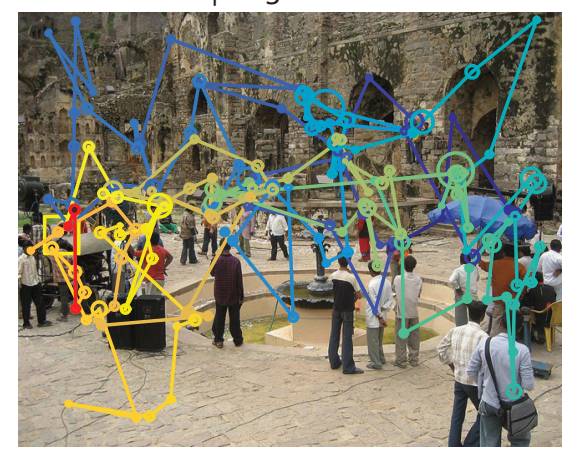

SWR: $31.2 \mathrm{~s}$ | Target detection: 38s
Trial start Trial end

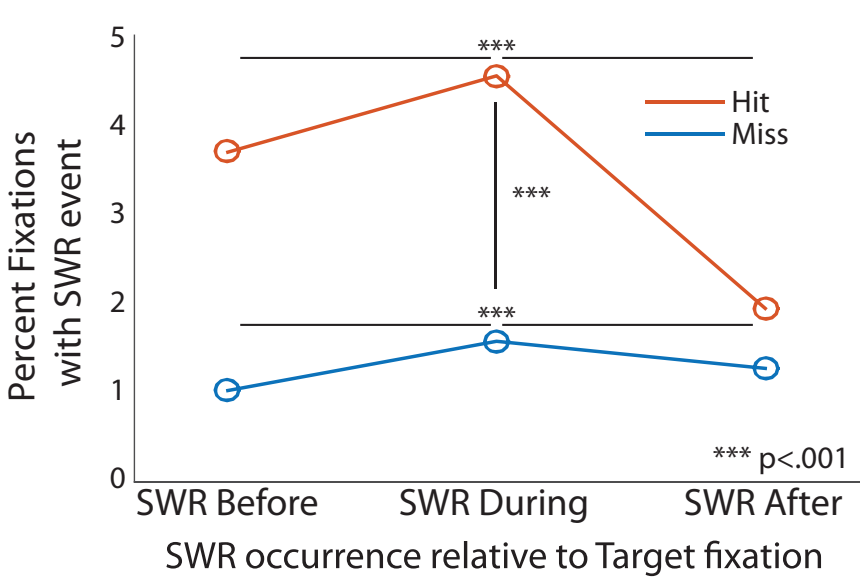

Figure 5. A, Four examples of scan paths during search in successful trials containing SWRs. Fixation (circles) and saccades (lines) with graded coloring according to the scan path (blue, trial start; yellow, trial end), with fixation duration represented by circle size. The nearest fixation in time to the SWR event is shown in black outlined in red, with the flanking fixations and saccades indicated by red only. The elapsed search time when the SWR occurred, and total search time until the target was detected, are listed below each image. $\boldsymbol{B}$, SWR occurrence, as a function of scan path distance from fixations directed in the target location. Fractional occurrence is shown separately for trials that were successful or unsuccessful (hits, red; misses, blue). SWRs concurrent with target fixations, shown in the middle group, had more hits than misses (vertical black significance bar). For a given detection type (hit/miss), the percentage of nonconcurrent SWRs (9 fixations preceding, and 9 subsequent to, the target fixation window) were compared with the percentage concurrent with target fixations (horizontal black significance bars).

durations that could extend into the adjacent fixation, "concurrent" SWRs are those whose peak time is within 1 fixation of the target fixation. These occurrences were subdivided by the outcome of the trial. That is, if the target detection was successful ("hit") or unsuccessful ("miss," defined as when maximum trial time was reached without detection). Concurrent target fixation and SWR rates were compared for hits and misses, using a rank-sum test. In addition, for a given detection type, the rates for nonconcurrent SWRs (nine fixations before and after the fixation window) were collapsed and compared with the SWR rates concurrent with target fixations, using a rank-sum test. All tests within a detection group were 
A

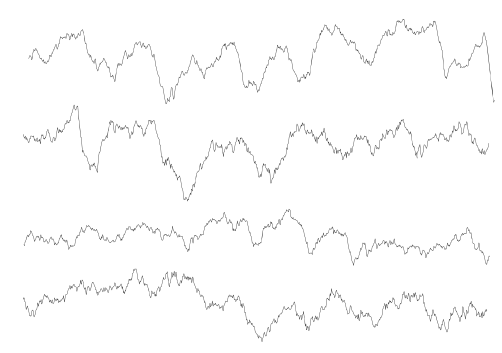

C
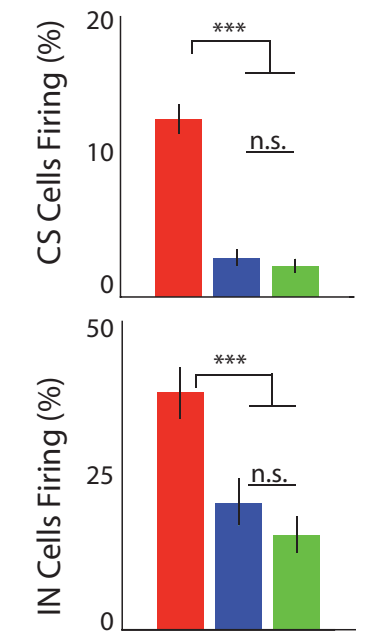

SWR Low $\varepsilon_{80-120 \mathrm{~Hz}}$

High $\varepsilon_{110-160 \mathrm{~Hz}}$

*** $p<0.001$
B

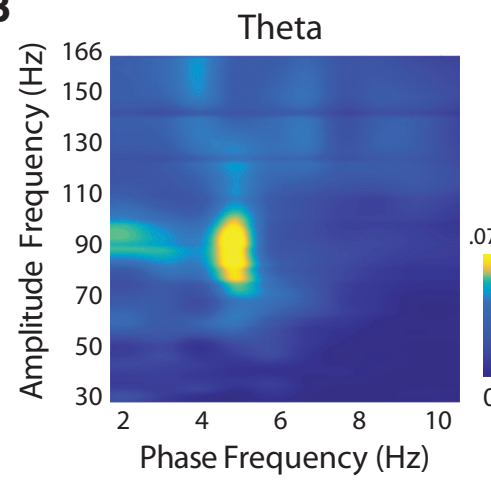

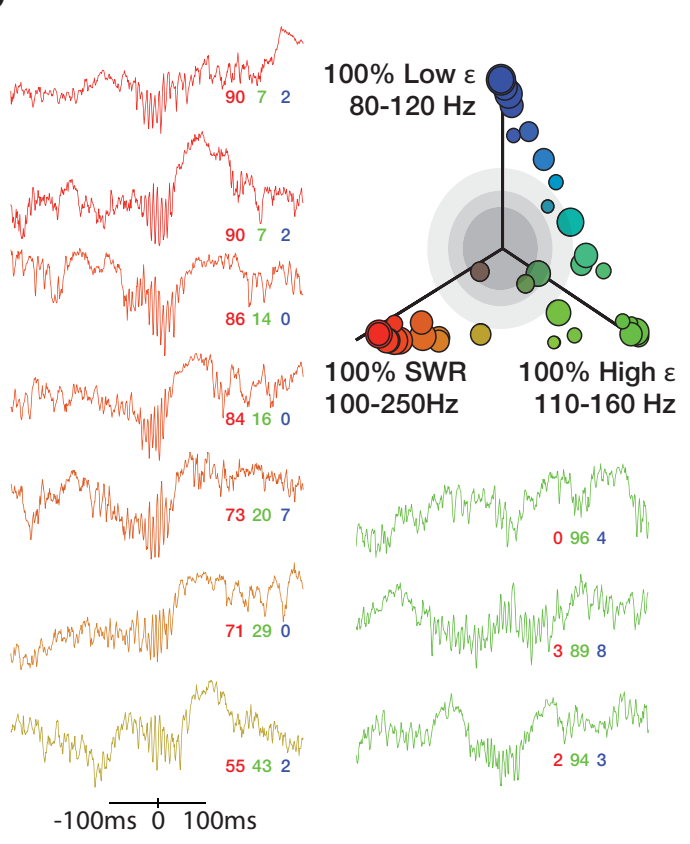
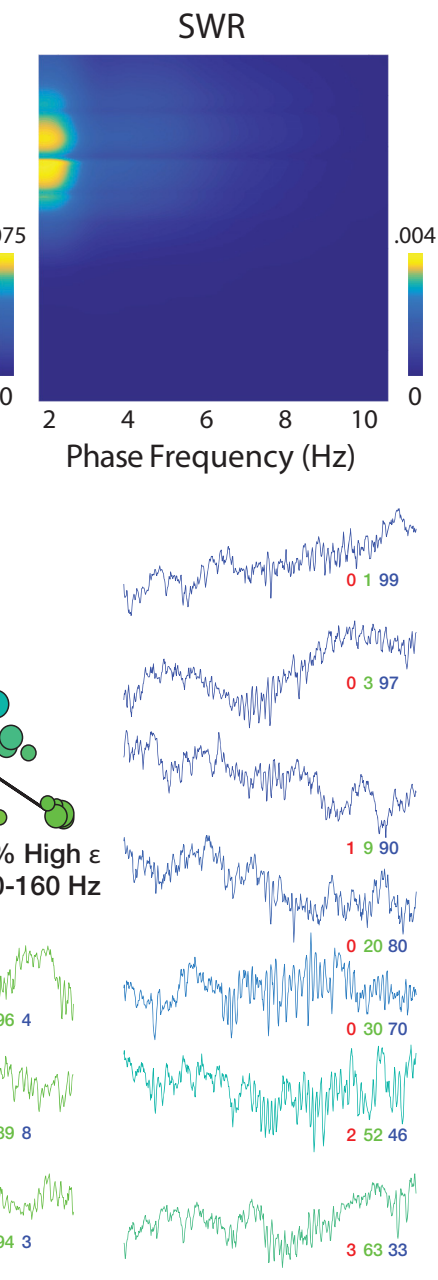

Figure 6. $A$, Example broadband LFP traces of theta oscillations for $\mathrm{m} 1$, used to generate comodulograms in $\boldsymbol{B}$. $\boldsymbol{B}$, Comodulogram showing the MI for each phase frequency by amplitude envelope frequency. The left plot used $2000 \mathrm{~ms}$ segments of theta events; the right plot used $600 \mathrm{~ms}$ of signal around SWR events, concatenated across events for sufficient phase-bin sampling (see Materials and Methods). C, The probability of spiking was greater for SWR than for $\varepsilon$ events. Bars show firing probability during peak SWR, $\varepsilon_{80-120}$, and $\varepsilon_{110-160}$ windows, for CS and IN cells, following same methods as in Figure 4; SWR bars are also shown in Figure 4, duplicated here for comparison to $\varepsilon$ events. Error bars reflect $95 \%$ confidence intervals. D, Events were clustered based on their NMF feature weights (see Materials and Methods). Middle plot shows the comparison of original group labels (SWR, high $\varepsilon$, low $\varepsilon$ ) by unsupervised clustering of all high-frequency events. Cluster position is defined by the percentage of members from each original group, with each group assigned to one axis, red- green- blue color-coded by axis position. Raw traces of the events that were closest to the center of their clusters are shown in the color corresponding to their cluster, with proportion of group representation shown below the trace. Dark-gray, gray, and light-gray spheres correspond to $p<0.5, p<0.01$, and $p<0.001$ significance rate boundaries, respectively.

corrected for false discovery rate with the Benjamini-Hochberg procedure. $\mathrm{A} \chi^{2}$ test was used to assess the probability of observing the frequency of trials that were hits or misses, for trials with both SWRs and fixations in target, and the probability of the observed frequency of these trials, which were hits or misses, for which SWRs and fixations in target coincided.

Comparing SWRs to high-gamma oscillations and HFOs $\left(\varepsilon_{80-120}\right.$, $\left.\varepsilon_{110-160}\right)$. To explore whether ripple frequencies during SWRs overlap with theta-modulated gamma-band frequencies, we generated comodulograms using a modified version of Tort et al.'s (2010) modulation index (MI; Fig. 6B). The MI measures how the amplitude of one frequency band varies as a function of the phase of another band, expressed as divergence from uniformity, i.e., no relation between the two. The MI calculation takes the mean amplitude of a given narrowband signal for several equally sized phase bins over $[0,2 \pi]$. For each bin, a probability term is created, defined as the mean amplitude from one bin divided by the sum of mean amplitudes from all bins. The Kullback-Leibler divergence from a uniform probability distribution for normalization (NKLD) is calculated on these probability terms.

The MI requires sufficient phase-bin sampling but the typical SWR event is one "sharp-wave" cycle in duration, whereas our typical primate theta bursts are $3-10$ cycles in duration. As a modification, we concatenated the amplitude means for each signal at the same respective phase bin across multiple signals within the same category into a phase-specific vector, and used the respective mean and sum of this vector for the NKLD. We then used the same general signal-processing procedures and analytic parameters from Tort et al. (2008), including bidirectional filtering and eegfilt Matlab toolbox parameters. Finite impulse response design parameters were as follows: phase frequency: $2 \mathrm{~Hz}$ passband in 1 $\mathrm{Hz}$ increments from 1 to $30 \mathrm{~Hz}$; amplitude frequency: $4 \mathrm{~Hz}$ passband in 2 $\mathrm{Hz}$ increments from 30 to $170 \mathrm{~Hz}$; all with three-cycle filter order of the lower passband cutoff frequency. For each SWR event we included 600 $\mathrm{ms}$ of centered processed signal and $2000 \mathrm{~ms}$ of each theta bout event.

To extract features of the high-frequency events, we first applied a multiresolution time-frequency analysis using a Hamming window of three cycles (Shuren Qin, 2004). For each event, spectrograms were generated from $50-180 \mathrm{~Hz}$ in $2 \mathrm{~Hz}$ nonoverlapping frequency bins, and $\pm 100 \mathrm{~ms}$ intervals sliding in $1 \mathrm{~ms}$ increments. To ensure that features from both higher and lower frequencies in the $50-180 \mathrm{~Hz}$ band could be detected, event spectrograms were min-max normalized separately for $50-110$ and $110-180 \mathrm{~Hz}$. The resulting patterns for 
Table 1. isWR rates

\begin{tabular}{lllllll}
\hline Group 1 & Group 2 & $p$ (corrected) & $U$ & $n$ & Group 1 mean & Group 2 mean \\
\hline $5 s$ & $10 s$ & 0.032 & 16 & 5 & 0.159 & 0.397 \\
$5 \mathrm{~s}$ & $15 \mathrm{~s}$ & 0.032 & 15 & 5 & 0.159 & 0.759 \\
$5 \mathrm{~s}$ & $20 \mathrm{~s}$ & 0.032 & 15 & 5 & 0.159 & 0.841 \\
$10 \mathrm{~s}$ & $15 \mathrm{~s}$ & 0.032 & 16 & 5 & 0.397 & 0.759 \\
$10 \mathrm{~s}$ & $20 \mathrm{~s}$ & 0.032 & 15 & 5 & 0.397 & 0.841 \\
$15 \mathrm{~s}$ & $20 \mathrm{~s}$ & 0.651 & 25 & 5 & 0.759 & 0.841
\end{tabular}

Paired comparisons for the SWR $5 \mathrm{~s}$ rate bins, for inactive behavioral epochs (eSWRs). All $p$ values corrected with Benjamini-Hochberg procedure.

\section{Table 2. eSWR rates}

\begin{tabular}{lllllll}
\hline Group 1 & Group 2 & $p$ (corrected) & $U$ & $n$ & Group 1 mean & Group 2 mean \\
\hline $5 s$ & $10 s$ & 0.032 & 15 & 5 & 0.317 & 0.888 \\
$5 \mathrm{~s}$ & $15 \mathrm{~s}$ & 0.032 & 15 & 5 & 0.317 & 0.874 \\
$5 \mathrm{~s}$ & $20 \mathrm{~s}$ & 0.032 & 15 & 5 & 0.317 & 1.120 \\
$10 \mathrm{~s}$ & $15 \mathrm{~s}$ & 0.548 & 31 & 5 & 0.888 & 0.874 \\
$10 \mathrm{~s}$ & $20 \mathrm{~s}$ & 0.444 & 21 & 5 & 0.888 & 1.120 \\
$15 \mathrm{~s}$ & $20 \mathrm{~s}$ & 0.444 & 21 & 5 & 0.874 & 1.120 \\
\hline
\end{tabular}

Paired comparisons for the SWR 5 s rate bins, for exploratory behavioral epochs (iSWRs). All $p$ values corrected with Benjamini-Hochberg procedure.

each event comprised the inputs to the non-negative matrix factorization (NMF) to extract the largest features across SWR and $\varepsilon$ events (Lee and Seung, 1999; Berry et al., 2007; Logothetis et al., 2012). Feature extraction used an alternating least-squares algorithm to produce 80 component factors.

Events were clustered based on their NMF feature weights using a self-organizing map that had a $5 \times 8$ rectangular topology and used Euclidean distance as an error function for training. For illustration of differences across clusters (Fig. $6 D$ ), we show the event with the lowest Mahalanobis distance to the centroid of each cluster.

This procedure effectively produces a time-frequency taxonomy of $\varepsilon$-band activity. To further investigate whether the time-frequency content of SWR events is distinct from that of other $\varepsilon$-band activity, we computed the group composition (SWR, $\varepsilon_{80-120}, \varepsilon_{110-160}$ ) for each of the 40 self-organizing map nodes and plotted them in a threedimensional group-membership space (Fig. $6 D$ ). We then used a permutation label-swapping (2000 permutations) between SWR, $\varepsilon_{80-120}$, and $\varepsilon_{110-160}$ events to compute a series of one-tailed significance tests.

\section{Results}

\section{Relation of SWR occurrence to behavioral states}

Based on the ripple-band threshold criteria (see Materials and Methods), SWRs were observed during task performance in all four macaques (Fig. 3A). m1 had 32 sessions with SWRs during both quiescence and task; $\mathrm{m} 2$ had 45 sessions with SWRs during both quiescence and task; m3 had 5 sessions with SWRs, only 3 of which had SWRs that occurred during the task; and m4 had 4 task-only sessions with SWRs. The eSWR oscillation's peak frequency did not differ from the peak frequencies of SWRs observed in the ITI, during inactivity (iSWRs) or during the start and end of the session quiescent states (qSWRs; $\chi_{(2)}^{2}=4.18, p=0.124$; Fig. $\left.3 B\right)$, suggesting that eSWRs share similar characteristics to more commonly described SWRs that occur during inactive states. In eSWR and iSWR epochs, SWRs occurred less frequently (i.e., lower rate) during the first $5 \mathrm{~s}$ of the epoch onset than at any other time point in the epoch (Tables 1 , 2; Fig. 3D). This pattern was similar to the comparatively low rate of SWRs seen in $\mathrm{m} 4$ during that animal's $2 \mathrm{~s}$ task epochs (search: $0.013 \mathrm{SWR} / \mathrm{min}$; rest: $0.011 \mathrm{SWR} / \mathrm{min}$ ). Finally, SWR events led to increased population synchrony (i.e., a decrease in firing sparsity) for both bursting CS cells and putative INs (CS: $w_{(28)}=26$,
Table 3. Logistic regression results

\begin{tabular}{lcl}
\hline & $Z$ & $P$ \\
\hline Subject & -1.85 & 0.065 \\
Saccade Amplitude & -2.74 & $0.006^{*}$ \\
Fixation Duration & 1.85 & 0.064 \\
Subject X Fixation Duration & 1.50 & 0.133 \\
Subject X Saccade Amplitude & 3.47 & $0.001^{*}$ \\
Saccade Amplitude X Fixation Duration & 1.22 & 0.221 \\
Subject X Saccade Amplitude X Fixation Duration & -2.22 & $0.026^{*}$
\end{tabular}

Results of logistic regression predicting the occurrence of SWRs from Fixation Duration, Saccade Amplitude, and Subject. Asterisks indicate significance. $\mathrm{df}=57,061$.

$p=4.2 \times 10^{-7} ; \mathrm{IN}: w_{(12)}=10, p=0.002$; Fig. 4$)$, similar to the increase observed in rodents (Csicsvari et al., 1998).

\section{Relation of SWR occurrence to search behaviors}

Within eSWR epochs, and contrary to expectation, SWRs occurred on screen during scene search and occurred preferentially during active scanning strategies. Scan path examples (Fig. 5A) show saccades and fixation durations that were typical for this task, and allow comparison to those seen during SWRs. Fixation durations during SWRs were $\sim 40 \mathrm{~ms}$ longer than for non-SWR fixations $\left(37.73 \mathrm{~ms}, z_{(2590)}=9.3, p=2.8 \times 10^{-20}\right)$, which is within typical search fixation durations and is more consistent with a local than a global search strategy. In addition, saccade amplitudes were smaller $\left(-0.51^{\circ}\right.$ visual angle, $z_{(1049)}=-3.3, p=$ 0.0009 ), also consistent with local search. SWRs were therefore more closely associated with active local search strategies than with protracted lapses in scanning or brief "inattentive" fixations. Using logistic regression to predict the occurrence of SWRs by fixation duration, saccade amplitude, and subject as a factor, we found that SWRs were predicted by the interaction of subject, saccade amplitude, and fixation duration, suggesting that (shorter) saccade amplitude and (longer) fixation duration contribute independently to SWR prediction, after accounting for subject. When all measures are held constant, there was a significant main effect of saccade amplitude, an interaction between saccade amplitude and subject, and an interaction between saccade amplitude, fixation duration, and subject (Table 3 ).

Although SWRs occurred during visual exploratory epochs, they may nevertheless signify brief interruptions in visual/perceptual processing, consistent with "off-line" states, albeit without interrupting search-related eye movements. Accordingly, if SWRs occurred when the target was fixated during search, perception of the target (hits) should be impaired. Alternatively, if SWRs are part of active exploratory activity and not interruptions of it, then their occurrence at times when the target is fixated may facilitate target detection. Finally, if the phenomenon is irrelevant to search, the timing of SWRs relative to target fixations should have no impact on target detection.

Overall, trials with $\geq 1$ SWR and $\geq 1$ target fixation during the search epoch were equally likely to be hits as misses $\left(n_{\text {hit }}: 150\right.$; $\left.n_{\text {miss }}: 153 ; \chi_{(1)}^{2}=0.005, p=0.909\right)$. In contrast, the subset of these trials with concurrent SWRs and target fixations were approximately twice as likely to be hits than misses $\left(\chi_{(1)}^{2}=9.2, p=0.002\right.$; Table 4). Closer examination of the timing of SWRs relative to target fixations during successful search revealed a higher rate of SWRs when concurrent with target fixation than the SWR rate when they were nonconcurrent with target fixations (hits: $z_{(2347)}$ $=-6.15, p=7.67 \times 10^{-10}$; misses: $z_{(2656)}=-5.08, p=3.71 \times$ $10^{-7}$; Fig. $\left.5 B\right)$. Finally, the rate of coincidence was higher for trials that were hits than for trials that were misses $\left(z_{(2347)}=-6.5, p=8.06 \times 10^{-11}\right.$; Fig. $\left.5 B\right)$, consistent with the 
Table 4. Coincident rates

\begin{tabular}{lrrr}
\hline & Hit & Miss & Total \\
\hline Coincident & 31 & 12 & 43 \\
Noncoincident & 119 & 141 & 260 \\
Total & 150 & 153 & \\
\hline
\end{tabular}

$\overline{\text { Trials with } \geq 1 \text { SWR and } \geq 1 \text { target fixation during search. Coincident is when the SWR and target fixation occurred }}$ together. Hit means successful search. Miss means unsuccessful search.

success-rate measure described above. Target fixations and SWRs are both relatively infrequent events. Nevertheless, when SWRs occur as targets are fixated, the target is more likely to be detected rather than overlooked, consistent with an association between SWRs and attentive perception.

\section{Relation of SWRs to other high-frequency events}

Prima facie, these results conflict with reports from rodent hippocampal physiology in which theta and various high gamma/ $\varepsilon$ band oscillations-not SWRs_- dominate during active task behaviors. One alternative account for the present findings would be that SWR detection, which is based on thresholding the power envelope in the 100-250 Hz range (see Materials and Methods), erroneously identified waking gamma/ $\varepsilon$ activity as SWR events. In contrast to SWRs, the $\varepsilon_{80-120}$ and $\varepsilon_{110-160}$ bands (high-gamma and HFOs) are expected to be weaker but more periodic, due to their modulation by theta oscillations (Scheffer-Teixeira et al., 2012). We therefore conducted three tests to determine whether the SWR events detected through conventional threshold methods might be more accurately described as theta high-frequency phenomena, or whether they show distinct spectral properties. Theta phase-gamma amplitude modulation has not been established in macaque hippocampus. We therefore first selected bouts of low-frequency activity during search and calculated the phase-amplitude MI for low-frequency phase and highfrequency amplitude modulations. This showed that $\sim 5 \mathrm{~Hz}$ theta-band phase modulates high-gamma amplitude, consistent with previous reports from the rat (Tort et al., 2013). Furthermore, a lower frequency "phase modulation" (due to the sharp wave peak that manifests at $2 \mathrm{~Hz}$ ) correlated with ripple amplitude variations, and the ripple frequency differed from the thetamodulated frequency. These results quantify that theta-band phases are related to a segregated gamma frequency band that differs from the ripple frequency band that is modulated during the sharp wave (Fig. 6B).

Second, we compared population synchrony across these high-frequency groups (Fig. 6C). We found that synchrony (decreased probability of firing) was enhanced selectively for SWRs, both for CS neurons $\left(\mathrm{SWR} / \varepsilon_{\mathrm{H}}: z_{(28)}=5.2, p=5.9 \times\right.$ $10^{-7}$; SWR $\left./ \varepsilon_{\mathrm{L}}: z_{(28)}=4.6, p=1.5 \times 10^{-5}\right)$ and putative INs $\left(\mathrm{SWR} / \varepsilon_{\mathrm{H}}: z_{(12)}=3.5, p=0.0014 ; \mathrm{SWR} / \varepsilon_{\mathrm{L}}: z_{(12)}=3.0, p=\right.$ 0.0073 ), and was not different between $\varepsilon$ bands (CS: $\varepsilon_{\mathrm{H}} / \varepsilon_{\mathrm{L}}$ : $\left.z_{(28)}=-0.58, p=1.7 ; \varepsilon_{\mathrm{H}} / \varepsilon_{\mathrm{L}}: z_{(12)}=-1.1, p=0.27\right)$.

Finally, using these same group definitions of high-frequency events (SWR, $\varepsilon_{80-120}, \varepsilon_{110-160}$ ) we visualized group differences, with a data-driven feature extraction that spanned $\pm 100 \mathrm{~ms}$ across the $50-180 \mathrm{~Hz}$ frequency band of each event, regardless of group label, and then clustered the events in feature space (see Materials and Methods). For visualization, we projected each cluster in a 3-D space according to the percentage membership from the original event labels; thus, the distance of a cluster from the center suggests nonrandom assignment into clusters. For example, if all events of a cluster came from the SWR group, it would appear at maximal eccentricity along the SWR axis (100, 0,
0 ). Most of the clusters (33 of 40 ) had $\geq 90 \%$ overlap with one of the original group labels (Fig. 6D), suggesting that the highfrequency content alone within a small (200 ms) window contains spectrotemporal features that separate ripples from other $\left(\varepsilon_{80-120}, \varepsilon_{110-160}\right)$ high-frequency events.

\section{Discussion}

SWRs occurred during goal-directed visual behaviors in macaques, specifically during visual exploration. These SWRs were similar in frequency and spectral content to those seen during periods of inactivity and sleep, but differed from rat eSWRs in their apparent behavioral correlates during the task. Macaque SWRs, like their rodent counterparts, appeared during inactive states. However, in addition, we observed SWRs during active visual search that was not associated with pauses in scanning. This raised two questions: (1) Were these detected events "true" SWRs, sharing the features of SWRs in inactive states and not high-frequency $\varepsilon$-band activity? and (2) Are these eSWRs related to search behaviors?

The comparison of SWR events to other high-frequency events revealed several differences among these groups. First, SWRs events had greater spiking probability than either the highgamma $\varepsilon_{80-120}$ or the HFO $\varepsilon_{110-160}$ group (Fig. 6C). Second, isolated theta-band bouts showed a theta modulation of highgamma amplitude frequency $(80-100 \mathrm{~Hz})$ that differed from the sharp wave-dependent amplitude frequency of SWRs $(\sim 125 \mathrm{~Hz}$; Fig. 6B; left, theta; right, SWR; Tort et al., 2013). The separation of peaks between the two comodulograms suggests that eSWRs can be segregated from theta-gamma modulation. Third, the data-driven classification of high-frequency events yielded a clustering of those events that had been designated as SWRs using conventional criteria (Fig. 6D). The clustering was nonrandom, and the SWR clusters had very little contamination by events that lacked the sharp-wave appearance and thus validated the accuracy of the SWR events we analyzed. Indeed, the few clusters that contained events from both SWR-labeled and high- $\varepsilon$-labeled groups appeared to be SWR clusters, but with lower-amplitude members that were subthreshold for inclusion as SWRs (i.e., false negatives). This method, therefore, may be useful for better signal detection and extraction of SWRs than conventional amplitudeenvelope threshold methods, and for isolating consistent spectrotemporal classes of SWRs that may be produced by different underlying neural populations.

SWRs varied with behavioral states. More specifically, subsets of SWRs were linked to active scanning processes of the visual environment. Previous studies have shown that scan paths during image viewing can be divided into global and local categories based on saccade amplitude (Unema et al., 2005). Local fixations are associated with longer fixation durations and more effective encoding of the foveated part of the image (the center of gaze), leading to better subsequent memory (Velichkovsky et al., 2005; van der Linde et al., 2009). SWRs during visual search epochs were associated with smaller saccades and longer fixation durations, all of which are paradoxically more consistent with attentive processing of the scene than with distracted or inactive behaviors. Whereas SWRs could occur while searching anywhere on the image, the target location is where the change lies and its fixation predicts successful detection. SWRs occurring concurrently with target fixations were more than twice as likely on successful as on unsuccessful trials. Successful trials also had higher SWR rate concurrent with target fixations than the SWR rate for the scan path fixations well in advance of or following target fixations 
(Fig. 5B). This finding suggests that the timing of SWRs relative to target fixations mattered. We speculate that SWRs did not impair processing of concurrently viewed parts of the image; on the contrary, if SWRs and target fixations occurred during a trial, the SWRs "on the target" facilitated detection.

A consideration about SWRs reported in this study, and of those reported in other studies, is the rate of SWR occurrences, which in primates is on the order of several times a minute. In these difficult tasks, search could last 10s of seconds, and up to $45 \mathrm{~s}$. The elapsed time analysis indicated that SWRs may not occur in tasks lasting only a few seconds [possibly explaining their absence in Skaggs et al. (2007)]. In our change-detection task, SWRs were detected every few trials on average, sometimes several per trial, but often none. As with eSWR occurrence during tasks in rodents, the SWRs may not occur for several trials, and performance (including learning) can occur without, or in between, detected SWRs. Therefore they cannot be considered critical mediators of task performance.

The rate of these phenomena, however, may be underestimated using current methods. SWRs in rats may occur independently along the septotemporal axis (Patel et al., 2013). The macaque hippocampal length along the long axis is many times greater than in rats and there is an elaboration of the anterior portion, along with a reduction in the hippocampal commissure, all of which may produce substantially more independent SWR events than what is seen in the rat. In this study, we report SWRs recorded from one position per session. Therefore, nonlocally generated SWRs could have gone undetected. Furthermore, the classification analysis clustered some events that appeared like SWRs, but were subthreshold for the SWR-detection procedure. Therefore false negatives may also contribute to an underestimate of SWR rate. The reduction in SWR power with increased running speed may exacerbate the false negatives for exploratory SWRs in rats (Kemere et al., 2013). Together, SWRs may be more frequent than currently reported, but should nevertheless be considered rare phenomena that carry considerable impact when they occur (Chrobak and Buzsáki, 1994; Siapas and Wilson, 1998; Sirota et al., 2003; Battaglia et al., 2004; Isomura et al., 2006; Mölle et al., 2006; Logothetis et al., 2012; Buzsáki, 2015).

We also note that our study does not resolve the direction of the relation between behavioral and eSWR events. Local search strategies may engender brain states conducive to SWR generation. Likewise, general brain states that lead to better search may also increase SWR rates. SWRs, therefore, may be a reflection of - rather than a facilitator of - successful search. The increased SWR rate specific to target fixations is more difficult to account for in this manner, but those events are only one subset of all SWRs observed.

Given the role of SWRs in large-scale neocortical synchrony, their role in synchronous hippocampal pyramidal cell reactivation, and their posited role in "off-line" synaptic plasticity and memory consolidation (Buzsáki, 2015), the presence of SWRs in the midst of active search is somewhat surprising. Either these events allow for continued sensory processing as posited for encoding, or else the transition to/from off-line states is more nimble than previously appreciated. Such rapid transitions are not unheard of in the hippocampus (Jezek et al., 2011; Kemere et al., 2013) and would allow eSWRs to provide a unique mechanism for timing long-range coordinated activity during experience (Hoffman and McNaughton, 2002; Sirota et al., 2003; Battaglia et al., 2004, 2011; Logothetis et al., 2012; Womelsdorf, 2015). In primates, as in rodents, this may prove to be important for learning during exploration. Alternatively, these infrequent but pow- erful events may occasionally "slip through" in active waking, and provide some as-yet-undescribed means of potentiating neurons selectively active when viewing the target location.

Either way, SWRs during visual-task performance may have important consequences to single-unit responses and BOLD activation in the hippocampus and neocortex. It is standard preprocessing in hippocampal physiology to filter for movement and/or theta-band LFP in rodent studies of place-field activity, thereby avoiding contamination by SWR-related activation. If primates have SWRs during active portions of a task, the response selectivity ("place fields" or "view cells") described in those segments may be artificially inflated by the SWR. For example, if SWRs occur with uneven sampling over the stimulus response space, such as at goal locations in a scene or virtual environment, those regions may appear to have place/view fields. This scenario would also predict that population level activation measures, such as the hippocampal BOLD response, could be affected by SWR occurrences as a function of task performance (Logothetis et al., 2012). These possibilities are purely speculative, but if several-fold changes in ongoing signal occurs-as observed during SWRs - they could affect results and warrant consideration.

One of the most striking differences between studies of SWRs in primates and those in rats and mice is the behavioral methodology. The rat and mouse studies of SWRs use running to indicate active task behavior, and filter out fast movement epochs when detecting SWRs. In contrast, very few of the hippocampaldependent tasks in humans and monkeys involve locomotion. Furthermore, memories that require hippocampal integrity do not need to be encoded or retrieved during self-movement through space. Imagine if memory for the personally experienced past required this: our desks and blackboards in school, our TVs, movie screens, and video-streaming laptops would need to be anchored to treadmills, or require that we watch as we walk. Indeed, humans and other primates extract much of what we know from our environment based on what we view, and not necessarily what we're actively ambulating toward or away from. That said, locomotion is an important aspect to hippocampal activity that may even be conserved across species, and hippocampal contributions to navigation may also be conserved. Yet, even if that is the case, we need an account for the memories we form that appear to be hippocampal dependent and yet do not require locomotor or ambulatory movement. SWRs occurring during periods of active, attentive visual exploration may serve some role in memory independent of locomotion, suggesting a more general or widespread role than previously thought.

\section{Notes}

Supplemental material for this article is available at http://yorku.ca/khoffman/video/: Example movies of SWRs during search and code base for high-frequency event feature/clustering methods. This material has not been peer reviewed.

\section{References}

Andrillon T, Nir Y, Cirelli C, Tononi G, Fried I (2015) Single-neuron activity and eye movements during human REM sleep and awake vision. Nat Commun 6:7884. CrossRef Medline

Axmacher N, Elger CE, Fell J (2008) Ripples in the medial temporal lobe are relevant for human memory consolidation. Brain 131:1806-1817. CrossRef Medline

Bartlett AM, Ovaysikia S, Logothetis NK, Hoffman KL (2011) Saccades during object viewing modulate oscillatory phase in the superior temporal sulcus. J Neurosci 31:18423-18432. CrossRef Medline

Battaglia FP, Sutherland GR, McNaughton BL (2004) Hippocampal sharp wave bursts coincide with neocortical "up-state" transitions. Learn Mem 11:697-704. CrossRef Medline 
Battaglia FP, Benchenane K, Sirota A, Pennartz CM, Wiener SI (2011) The hippocampus: hub of brain network communication for memory. Trends Cogn Sci 15:310-318. CrossRef Medline

Benchenane K, Peyrache A, Khamassi M, Tierney PL, Gioanni Y, Battaglia FP, Wiener SI (2010) Coherent theta oscillations and reorganization of spike timing in the hippocampal-prefrontal network upon learning. Neuron 66:921-936. CrossRef Medline

Benjamini Y, Hochberg Y (1995) Controlling the false discovery rate: a practical and powerful approach to multiple testing. J R Stat Soc Ser B 57:289-300.

Berry M, Browne M, Langville A, Pauca V, Plemmons R (2007) Algorithms and applications for approximate nonnegative matrix factorization. Comput Stat Data Anal 52:155-173. CrossRef

Blumberg MS (1989) An allometric analysis of the frequency of hippocampal theta: the significance of brain metabolic rate. Brain Behav Evol 34: 351-356. CrossRef Medline

Bódizs R, Kántor S, Szabó G, Szûcs A, Erõss L, Halász P (2001) Rhythmic hippocampal slow oscillation characterizes REM sleep in humans. Hippocampus 11:747-753. CrossRef Medline

Bragin A, Engel J Jr, Wilson CL, Fried I, Buzsáki G (1999) High-frequency oscillations in human brain. Hippocampus 9:137-142. CrossRef Medline

Bridgeman B, Hendry D, Stark L (1975) Failure to detect displacement of the visual world during saccadic eye movements. Vision Res 15:719-722. CrossRef Medline

Buzsáki G (1986) Hippocampal sharp waves: their origin and significance. Brain Res 398:242-252. CrossRef Medline

Buzsáki G (1989) Two-stage model of memory trace formation: a role for "noisy" brain states. Neuroscience 31:551-570. CrossRef Medline

Buzsáki G (1996) The hippocampo-neocortical dialogue. Cereb Cortex 6:81-92. CrossRef Medline

Buzsáki G (2015) Hippocampal sharp wave-ripple: a cognitive biomarker for episodic memory and planning. Hippocampus 25:1073-1188. CrossRef Medline

Buzsáki G, Schomburg EW (2015) What does gamma coherence tell us about inter-regional neural communication? Nat Neurosci 18:484-489. CrossRef Medline

Buzsáki G, Leung LW, Vanderwolf CH (1983) Cellular bases of hippocampal EEG in the behaving rat. Brain Res 287:139-171. Medline

Cantero JL, Atienza M, Stickgold R, Kahana MJ, Madsen JR, Kocsis B (2003) Sleep-dependent theta oscillations in the human hippocampus and neocortex. J Neurosci 23:10897-10903. Medline

Carr MF, Jadhav SP, Frank LM (2011) Hippocampal replay in the awake state: a potential substrate for memory consolidation and retrieval. Nat Neurosci 14:147-153. CrossRef Medline

Chau VL, Murphy EF, Rosenbaum RS, Ryan JD, Hoffman KL (2011) A flicker change detection task reveals object-in-scene memory across species. Front Behav Neurosci 5:58. CrossRef Medline

Chrobak JJ, Buzsáki G (1994) Selective activation of deep layer (V-VI) retrohippocampal cortical neurons during hippocampal sharp waves in the behaving rat. J Neurosci 14:6160-6170. Medline

Clemens Z, Borbély C, Weiss B, Erõss L, Szûcs A, Kelemen A, Fabó D, Rásonyi G, Janszky J, Halász P (2013) Increased mesiotemporal delta activity characterizes virtual navigation in humans. Neurosci Res 76:67-75. CrossRef Medline

Csicsvari J, Hirase H, Czurko A, Buzsáki G (1998) Reliability and state dependence of pyramidal cell-interneuron synapses in the hippocampus: an ensemble approach in the behaving rat. Neuron 21:179-189. CrossRef Medline

Csicsvari J, Hirase H, Czurkó A, Mamiya A, Buzsáki G (1999) Fast network oscillations in the hippocampal CA1 region of the behaving rat. J Neurosci 19:RC20. Medline

Csicsvari J, Hirase H, Mamiya A, Buzsáki G (2000) Ensemble patterns of hippocampal CA3-CA1 neurons during sharp wave-associated population events. Neuron 28:585-594. CrossRef Medline

Dupret D, O’Neill J, Pleydell-Bouverie B, Csicsvari J (2010) The reorganization and reactivation of hippocampal maps predict spatial memory performance. Nat Neurosci 13:995-1002. CrossRef Medline

Ego-Stengel V, Wilson MA (2010) Disruption of ripple-associated hippocampal activity during rest impairs spatial learning in the rat. Hippocampus 20:1-10. CrossRef Medline

Foster DJ, Wilson MA (2006) Reverse replay of behavioural sequences in hippocampal place cells during the awake state. Nature 440:680-683. CrossRef Medline

Gerrard JL, Kudrimoti H, McNaughton BL, Barnes CA (2001) Reactivation of hippocampal ensemble activity patterns in the aging rat. Behav Neurosci 115:1180-1192. CrossRef Medline

Girardeau G, Zugaro M (2011) Hippocampal ripples and memory consolidation. Curr Opin Neurobiol 21:452-459. CrossRef Medline

Girardeau G, Benchenane K, Wiener SI, Buzsáki G, Zugaro MB (2009) Selective suppression of hippocampal ripples impairs spatial memory. Nat Neurosci 12:1222-1223. CrossRef Medline

Harris KD, Henze DA, Csicsvari J, Hirase H, Buzsáki G (2000) Accuracy of tetrode spike separation as determined by simultaneous intracellular and extracellular measurements. J Neurophysiol 84:401-414. Medline

Henderson JM, Williams CC, Falk RJ (2005) Eye movements are functional during face learning. Mem Cognit 33:98-106. CrossRef Medline

Hoffman KL, McNaughton BL (2002) Coordinated reactivation of distributed memory traces in primate neocortex. Science 297:2070-2073. CrossRef Medline

Hoffman KL, Battaglia FP, Harris K, MacLean JN, Marshall L, Mehta MR (2007) The upshot of up states in the neocortex: from slow oscillations to memory formation. J Neurosci 27:11838-11841. CrossRef Medline

Hoffman KL, Dragan MC, Leonard TK, Micheli C, Montefusco-Siegmund R, Valiante TA (2013) Saccades during visual exploration align hippocampal 3-8 Hz rhythms in human and non-human primates. Front Syst Neurosci 7:43. CrossRef Medline

Ibbotson M, Krekelberg B (2011) Visual perception and saccadic eye movements. Curr Opin Neurobiol 21:553-558. CrossRef Medline

Ibbotson MR, Crowder NA, Cloherty SL, Price NS, Mustari MJ (2008) Saccadic modulation of neural responses: possible roles in saccadic suppression, enhancement, and time compression. J Neurosci 28:10952-10960. CrossRef Medline

Isomura Y, Sirota A, Ozen S, Montgomery S, Mizuseki K, Henze DA, Buzsáki G (2006) Integration and segregation of activity in entorhinalhippocampal subregions by neocortical slow oscillations. Neuron 52: 871-882. CrossRef Medline

Jackson J, Goutagny R, Williams S (2011) Fast and slow $\gamma$ rhythms are intrinsically and independently generated in the subiculum. J Neurosci 31: 12104-12117. CrossRef Medline

Jadhav SP, Kemere C, German PW, Frank LM (2012) Awake hippocampal sharp-wave ripples support spatial memory. Science 336:1454-1458. CrossRef Medline

Jezek K, Henriksen EJ, Treves A, Moser EI, Moser MB (2011) Theta-paced flickering between place-cell maps in the hippocampus. Nature 478: 246-249. CrossRef Medline

Ji D, Wilson MA (2007) Coordinated memory replay in the visual cortex and hippocampus during sleep. Nat Neurosci 10:100-107. CrossRef Medline

Jutras MJ, Fries P, Buffalo EA (2013) Oscillatory activity in the monkey hippocampus during visual exploration and memory formation. Proc Natl Acad Sci U S A 110:13144-13149. CrossRef Medline

Kemere C, Carr MF, Karlsson MP, Frank LM (2013) Rapid and continuous modulation of hippocampal network state during exploration of new places. PloS One 8:e73114. CrossRef Medline

Kudrimoti HS, Barnes CA, McNaughton BL (1999) Reactivation of hippocampal cell assemblies: effects of behavioral state, experience, and EEG dynamics. J Neurosci 19:4090-4101. Medline

Le Van Quyen M, Bragin A, Staba R, Crépon B, Wilson CL, Engel J Jr (2008) Cell type-specific firing during ripple oscillations in the hippocampal formation of humans. J Neurosci 28:6104-6110. CrossRef Medline

Le Van Quyen M, Staba R, Bragin A, Dickson C, Valderrama M, Fried I, Engel J (2010) Large-scale microelectrode recordings of high-frequency gamma oscillations in human cortex during sleep. J Neurosci 30:77707782. CrossRef Medline

Lee DD, Seung HS (1999) Learning the parts of objects by non-negative matrix factorization. Nature 401:788-791. CrossRef Medline

Logothetis NK, Eschenko O, Murayama Y, Augath M, Steudel T, Evrard HC, Besserve M, Oeltermann A (2012) Hippocampal-cortical interaction during periods of subcortical silence. Nature 491:547-553. CrossRef Medline

Louie K, Wilson MA (2001) Temporally structured replay of awake hippocampal ensemble activity during rapid eye movement sleep. Neuron 29:145-156. CrossRef Medline 
Matin E (1974) Saccadic suppression: a review and an analysis. Psychol Bull 81:899-917. CrossRef Medline

McConkie GW, Currie CB (1996) Visual stability across saccades while viewing complex pictures. J Exp Psychol Hum Percept Perform 22:563581. CrossRef Medline

Mölle M, Yeshenko O, Marshall L, Sara SJ, Born J (2006) Hippocampal sharp wave-ripples linked to slow oscillations in rat slow-wave sleep. J Neurophysiol 96:62-70. CrossRef Medline

Moroni F, Nobili L, Curcio G, De Carli F, Fratello F, Marzano C, De Gennaro L, Ferrillo F, Cossu M, Francione S, Lo Russo G, Bertini M, Ferrara M (2007) Sleep in the human hippocampus: a stereo-EEG study. PloS One 2:e867. CrossRef Medline

Mruczek RE, Sheinberg DL (2007) Activity of inferior temporal cortical neurons predicts recognition choice behavior and recognition time during visual search. J Neurosci 27:2825-2836. CrossRef Medline

O'Neill J, Senior T, Csicsvari J (2006) Place-selective firing of CA1 pyramidal cells during sharp wave/ripple network patterns in exploratory behavior. Neuron 49:143-155. CrossRef Medline

O’Neill J, Pleydell-Bouverie B, Dupret D, Csicsvari J (2010) Play it again: reactivation of waking experience and memory. Trends Neurosci 33: 220-229. CrossRef Medline

Patel J, Schomburg EW, Berényi A, Fujisawa S, Buzsáki G (2013) Local generation and propagation of ripples along the septotemporal axis of the hippocampus. J Neurosci 33:17029-17041. CrossRef Medline

Peyrache A, Khamassi M, Benchenane K, Wiener SI, Battaglia FP (2009) Replay of rule-learning related neural patterns in the prefrontal cortex during sleep. Nat Neurosci 12:919-926. CrossRef Medline

Pezzulo G, van der Meer MA, Lansink CS, Pennartz CM (2014) Internally generated sequences in learning and executing goal-directed behavior. Trends Cogn Sci 18:647-657. CrossRef Medline

Pfeiffer BE, Foster DJ (2013) Hippocampal place-cell sequences depict future paths to remembered goals. Nature 497:74-79. CrossRef Medline

Pomplun M, Sichelschmidt L, Wagner K, Clermont T, Rickheit G, Ritter H (2001) Comparative visual search: a difference that makes a difference. Cogn Sci 25:3-36. CrossRef

Purpura KP, Kalik SF, Schiff ND (2003) Analysis of perisaccadic field potentials in the occipitotemporal pathway during active vision. J Neurophysiol 90:3455-3478. CrossRef Medline

Qin YL, McNaughton BL, Skaggs WE, Barnes CA (1997) Memory reprocessing in corticocortical and hippocampocortical neuronal ensembles. Philos Trans R Soc Lond B Biol Sci 352:1525-1533. CrossRef Medline

Ringo JL, Sobotka S, Diltz MD, Bunce CM (1994) Eye movements modulate activity in hippocampal, parahippocampal, and inferotemporal neurons. J Neurophysiol 71:1285-1288. Medline

Saleem KS, Logothetis NK (2012) A combined MRI and histology atlas of the rhesus monkey brain in stereotaxic coordinates. London: Academic.

Schad DJ, Nuthmann A, Engbert R (2012) Your mind wanders weakly, your mind wanders deeply: objective measures reveal mindless reading at different levels. Cognition 125:179-194. CrossRef Medline

Scheffer-Teixeira R, Belchior H, Caixeta FV, Souza BC, Ribeiro S, Tort AB (2012) Theta phase modulates multiple layer-specific oscillations in the CA1 region. Cereb Cortex 22:2404-2414. CrossRef Medline

Scinto LF, Pillalamarri R, Karsh R (1986) Cognitive strategies for visual search. Acta Psychol (Amst) 62:263-292. CrossRef

Shen C, Ardid S, Kaping D, Westendorff S, Everling S, Womelsdorf T (2015) Anterior cingulate cortex cells identify process-specific errors of attentional control prior to transient prefrontal-cingulate inhibition. Cereb Cortex 25:2213-2228. CrossRef Medline

Shuren Qin ZJ (2004) Multi-resolution time-frequency analysis for detection of rhythms of EEG signals. 2004 IEEE 11th Digital Signal Processing Workshop, Taos Ski Valley, NM, August.

Siapas AG, Wilson MA (1998) Coordinated interactions between hippocampal ripples and cortical spindles during slow-wave sleep. Neuron 21:1123-1128. CrossRef Medline

Singer AC, Carr MF, Karlsson MP, Frank LM (2013) Hippocampal SWR activity predicts correct decisions during the initial learning of an alternation task. Neuron 77:1163-1173. CrossRef Medline
Sirota A, Csicsvari J, Buhl D, Buzsáki G (2003) Communication between neocortex and hippocampus during sleep in rodents. Proc Natl Acad Sci U S A 100:2065-2069. CrossRef Medline

Skaggs WE, McNaughton BL, Permenter M, Archibeque M, Vogt J, Amaral DG, Barnes CA (2007) EEG sharp waves and sparse ensemble unit activity in the macaque hippocampus. J Neurophysiol 98:898-910. CrossRef Medline

Sobotka S, Nowicka A, Ringo JL (1997) Activity linked to externally cued saccades in single units recorded from hippocampal, parahippocampal, and inferotemporal areas of macaques. J Neurophysiol 78:2156-2163. Medline

Sobotka S, Zuo W, Ringo JL (2002) Is the functional connectivity within temporal lobe influenced by saccadic eye movements? J Neurophysiol 88:1675-1684. Medline

Sullivan D, Csicsvari J, Mizuseki K, Montgomery S, Diba K, Buzsáki G (2011) Relationships between hippocampal sharp waves, ripples, and fast gamma oscillation: influence of dentate and entorhinal cortical activity. J Neurosci 31:8605-8616. CrossRef Medline

Tamura R, Nishida H, Eifuku S, Fushiki H, Watanabe Y, Uchiyama K (2013) Sleep-stage correlates of hippocampal electroencephalogram in primates. PloS One 8:e82994. CrossRef Medline

Tole JR, Stephens AT, Harris RL Sr, Ephrath AR (1982) Visual scanning behavior and mental workload in aircraft pilots. Aviat Space Environ Med 53:54-61. Medline

Tort AB, Kramer MA, Thorn C, Gibson DJ, Kubota Y, Graybiel AM, Kopell NJ (2008) Dynamic cross-frequency couplings of local field potential oscillations in rat striatum and hippocampus during performance of a T-maze task. Proc Natl Acad Sci U S A 105:20517-20522. CrossRef Medline

Tort AB, Komorowski R, Eichenbaum H, Kopell N (2010) Measuring phase-amplitude coupling between neuronal oscillations of different frequencies. J Neurophysiol 104:1195-1210. CrossRef Medline

Tort AB, Scheffer-Teixeira R, Souza BC, Draguhn A, Brankaèk J (2013) Theta-associated high-frequency oscillations $(110-160 \mathrm{~Hz})$ in the hippocampus and neocortex. Prog Neurobiol 100:1-14. CrossRef Medline

Uchida S, Maehara T, Hirai N, Okubo Y, Shimizu H (2001) Cortical oscillations in human medial temporal lobe during wakefulness and all-night sleep. Brain Res 891:7-19. CrossRef Medline

Unema PJ, Pannasch S, Joos M, Velichkovsky BM (2005) Time course of information processing during scene perception: the relationship between saccade amplitude and fixation duration. Vis Cogn 12:473-494. CrossRef

van der Linde I, Rajashekar U, Bovik AC, Cormack LK (2009) Visual memory for fixated regions of natural images dissociates attraction and recognition. Perception 38:1152-1171. CrossRef Medline

Vanderwolf $\mathrm{CH}$ (1969) Hippocampal electrical activity and voluntary movement in the rat. Electroencephalogr Clin Neurophysiol 26:407-418. CrossRef Medline

Velichkovsky BM, Joos M, Helmert JR, Pannasch S 2005Two visual systems and their eye movements: evidence from static and dynamic scene perception. In: Proceedings of the XXVII Conference of the Cognitive Science Society (Bara BG, Barsalou L, Bucciarelli M, eds), pp 2283-2288. Mahwah, NJ: Lawrence Erlbaum.

Whishaw IQ, Vanderwolf CH (1973) Hippocampal EEG and behavior: changes in amplitude and frequency of RSA (theta rhythm) associated with spontaneous and learned movement patterns in rats and cats. Behav Biol 8:461-484. CrossRef Medline

Wilson MA, McNaughton BL (1994) Reactivation of hippocampal ensemble memories during sleep. Science 265:676-679. CrossRef Medline

Winson J (1972) Interspecies differences in the occurrence of theta. Behav Biol 7:479-487. CrossRef Medline

Womelsdorf T, Everling S (2015) Long-range attention networks: circuit motifs underlying endogenously controlled stimulus selection. Trends Neurosci, in press.

Yu JY, Frank LM (2015) Hippocampal-cortical interaction in decision making. Neurobiol Learn Mem 117:34-41. CrossRef Medline 